\title{
O Conhecimento como Questão: o Papel da Epistemologia na Formação Superior
}

Sara Albieri*

Faculdade de Filosofia, Letras e Ciências Humanas da Universidade de São Paulo

* Autor para correspondência: sara@usp.br

\section{RESUMO}

No ensino escolar, o conhecimento científico é apresentado de forma dogmática, como um saber estabelecido que é preciso adquirir de um modo mais instrumental do que refletido. $\mathrm{O}$ aprofundamento exigido na formação superior depende de uma compreensão mais ampla da natureza do conhecimento a ser produzido. A introdução a noções relevantes de Epistemologia nos primeiros períodos da graduação pode suprir essa carência. A questão do conhecimento pode constituir com sucesso uma plataforma crítica comum para as diferentes áreas de investigação na universidade.

Palavras-chave: Conhecimento; Ciência; Epistemologia; Formação Superior.

\begin{abstract}
In middle school scientific knowledge is presented in a dogmatic way, as an established knowledge to be acquired more by instrumental means than reflected. The deeper level of contents required in higher education depends on a broader understanding of the nature of the knowledge to be produced. The introduction of relevant notions of Epistemology in the first periods of undergraduate studies can meet this need. The question of knowledge can contribute to successfully build a common critical platform to support the different areas of research at the University.
\end{abstract}

Keywords: Knowledge; Science; Epistemology; Higher Education.

Se há um território comum entre as muitas áreas de formação que compõem a universidade, este será o do conhecimento. Com efeito, entende-se que a universidade é o lugar social da produção do conhecimento avançado que chamamos ciência (SHAPIN, 1979; BURKE, 2013). E o conhecimento científico é oferecido como um leque de áreas e especialidades em prosseguimento da formação escolar, supondo uma certa "base" a ser oferecida aos estudantes durante o Ensino Básico e o Médio.

A estruturação do ensino preparatório costuma ser objeto de propostas e revisões periódicas, com diferentes enfoques e maior ou menor sucesso. Porém, a questão da formação científica parece seguir pouco tratada em suas vertentes constitutivas. Em regra, a ideia de conhecimento científico aparece associada fortemente às matemáticas e às ciências naturais. E embora se discutam métodos e materiais que possam aprimorar o interesse dos alunos ou a eficiência do aprendizado, esse conjunto de saberes científicos parece gozar de estatuto próprio e de imunidade crítica.

Quanto às ciências do homem, presume-se um tanto apressadamente que seu lugar natural coincida com as línguas, os estudos literários, as artes. E a discussão sobre a importância ou oportunidade de seu ensino com frequência oscila entre os que prezam as qualidades dessa formação um tanto ampla e aqueles que a situam nas franjas do supérfluo.

É verdade que os defensores das humanidades frequentemente destacam uma espécie de capacidade crítica que seria ali gestada, atenta a circunstâncias políticas, sociais, culturais, 
interferente e engajada. A partir desse lugar de crítica seria possível inclusive questionar o prestigiado papel social e institucional dos conhecimentos científicos - por exemplo, desvelando seus compromissos com interesses diversos, contrários à suposta imparcialidade da ciência. Ou então apontando os vieses que orientam as opções de pesquisa, ou ainda as brechas éticas tanto na condução das pesquisas quanto no emprego de seus resultados.

Contudo, tanto no âmbito da formação científica quanto naquele das humanidades, raramente é levantada a questão fundamental que é anterior à constituição mesma do campo de investigação das ciências em sua acepção moderna, ou no modo acadêmico contemporâneo, enquanto divisão disciplinar dos saberes. Trata-se de perguntar pela natureza daquilo que motiva a investigação como resultado a ser auferido ao longo do processo educacional: o conhecimento.

Isso nos faz remontar ao campo da Filosofia, lugar histórico da formação dos saberes modernos. Com efeito, é possível encontrar nessa longa tradição, que tem origem no pensamento grego, tanto o desejo da verdade quanto a riquíssima discussão sobre os meios de alcançá-la. Durante muito tempo os filósofos se dedicaram a esse estudo, que apresentava o nome de teoria do conhecimento. Mais contemporaneamente, e em meio a debates conceituais diversos - que não interessa recuperar aqui -, esse tipo de reflexão passou a denominar-se Epistemologia.

É frequente disciplinas e áreas reservarem algum espaço para uma epistemologia específica de seus saberes: ali apresentam definições, pressupostos, diretrizes metodológicas. Mas o que propomos recuperar aqui são conceitos e instrumentos pertencentes à epistemologia filosófica - aquela que, contemporaneamente, desenvolve a análise dos fundamentos e da estrutura teórica e conceitual do conhecimento previamente a sua divisão disciplinar.

O objetivo principal é colocar essa tradição em contato com procedimentos de investigação científica já incorporados e naturalizados, para que o espelhamento metateórico dessas concepções e práticas permita maior clareza na identificação de problemas, melhor emprego de materiais e métodos, aprimoramento da argumentação e, de modo geral, a compreensão consistente dos rumos e sentidos da investigação. Recuperar esses instrumentos analíticos pode resultar em vantagem para uma educação científica verdadeiramente crítica, portanto consistente com os mais elevados padrões de desenvolvimento do mais sólido travejamento que hoje sustenta o edifício das ciências todas.

Se é verdade que todos os homens têm por natureza o desejo de conhecer, como queria Aristóteles, esse impulso dificilmente será acolhido e aproveitado num ensino concebido mais como um treinamento que prima pelo acúmulo por memorização do que como um preparo para a investigação que decorra dessa motivação primeva pela busca do conhecimento.

As carências de tal ensino são conhecidas: equipamentos, laboratórios, informatização. A presença ou a falta desses materiais - e, por vezes, dos mestres para manuseá-los - ecoam nas avaliações das escolas, tanto públicas como privadas. O que inspira esse tipo de diagnóstico é uma espécie de otimização das capacidades operativas associadas a um acúmulo de informações apresentadas de forma não problematizada - providências bem distantes de uma formação. Tal visão da aquisição do conhecimento não decorre apenas do empobrecimento das humanidades. Há também o empobrecimento das ciências, ensinadas na forma de um adestramento cumulativo visando a resultados duvidosos, como a memorização provisória para sucesso em exames de ingresso no Ensino Superior.

A universidade recebe a maioria de seus alunos assim treinados. Não é preciso maior sagacidade para constatar que as virtudes epistêmicas foram gravemente descuradas. Sem elas, o ímpeto para a pesquisa criativa torna-se raro e tímido. $\mathrm{E} \mathrm{o}$ prosseguimento do ensino especializado entrava a possibilidade de sua recuperação.

Propomos aqui a apropriação pedagógica da tradição epistemológica para a formação de graduandos em todas as áreas. É possível identificar, em meio à produção filosófica de nosso tempo, o aprimoramento de instrumentos descendentes dessa 
tradição que poderiam constituir poderoso treinamento para a formação científica em sentido amplo. Talvez os meios mais conhecidos sejam aqueles relacionados à lógica enquanto argumentação, utilizados tanto como parte da formação regular em alguns cursos como em divulgação para o grande público. Desse gênero são também os cursos de critical thinking, desenhados para esse tipo de treinamento sobretudo em universidades norte-americanas (COPI, 1982; EPSTEIN, 1999; SALMON, 2013).

Menos comuns são as apresentações conceituais acerca dos fundamentos do conhecimento de um ponto de vista filosófico (CORNMAN, LEHRER \& PAPPAS, 1992; AUDI, 1998; APPIAH, 2003). Por seu caráter geral, prévio às abordagens específicas do conhecimento já enquanto objeto de ciências particulares - como as ciências da mente e da cognição -, esse material permite pavimentar o caminho de passagem entre a formação escolar e aquela universitária, entre as concepções de senso comum acerca da ciência e o trabalho especializado que será exigido do universitário.

\section{As Oficinas de Epistemologia}

Trata-se de oferecer uma introdução aos principais temas e problemas em Epistemologia, de modo a capacitar os alunos a identificarem e discutirem criticamente questões relativas à produção, à transmissão e ao emprego do conhecimento em suas diversas formas, acadêmicas e não acadêmicas.

A estrutura proposta é de quatro cursos temáticos:

\section{Percepção e Conhecimento;}

2. Razão e Experiência;

3. Lógica Informal, Retórica e Argumentação;

4. Conhecimento Científico.

Idealmente cada curso teria duração semestral, podendo ser oferecidos aos pares, ao longo do primeiro ano de graduação. Também poderiam ser elaboradas versões mais curtas, dependendo do aprofundamento desejado. As oficinas teriam estatuto de disciplinas optativas para todos os cursos, com ampla divulgação e encorajamento para matrícula.

Cada curso ofereceria uma breve apresentação teórica, destacando noções e conceitos-chave relacionados ao tema, procedendo à discussão pormenorizada. A fixação desses conteúdos decorreria dos muitos exercícios a serem conduzidos em sala, que permitiriam relacionar a teoria apresentada aos contextos específicos de aplicação potencial. Ênfases e exemplos poderiam ser adequados a cada grande área, ou mesmo a cada curso de graduação para o qual o módulo fosse ministrado.

À guisa de ilustração, apresentamos um esboço apenas esquemático de parte dos conteúdos a serem organizados nos módulos propostos. O conteúdo esboçado é uma elaboração crítica apoiada e adaptada a partir da bibliografia elencada.

\section{Temas Básicos de Epistemologia}

Percepção e Conhecimento (MUSGRAVE, 1993)

O papel dos sentidos para a aquisição do conhecimento é um tema central para a Epistemologia. Afinal, se há uma certeza que parece ser compartilhada por todos é a de que adquirimos conhecimento do mundo por meio de nossos sentidos: visão, tato, audição, olfato, paladar. Eles são as "janelas da alma" - eles nos informam acerca dos objetos e fatos que constituem o conhecimento por experiência.

A confiança na percepção dos objetos do mundo revelados pelos sentidos parece ser compartilhada por todos. Nossa vida comum é guiada por essa certeza. Contudo, os céticos, tanto antigos quanto modernos, apresentaram argumentos contra a credibilidade dos sentidos, baseados nos enganos e ilusões em que frequentemente incorremos na percepção dos objetos.

A questão epistêmica que se põe nesses casos é quanto aos critérios que fundamentariam a distinção entre aquelas percepções consideradas ilusórias ou alucinatórias e as outras consideradas normais, corretas ou verídicas. O fato é que consideramos verdadeiras aquelas qualidades 
percebidas segundo certas condições tomadas como padrão. Também corrigimos os "erros" dos sentidos utilizando nossos conhecimentos mais gerais e bem-fundamentados acerca do mundo e da natureza.

\section{Razão e Experiência}

Como adquirimos conhecimento? As inúmeras respostas dadas a essa questão podem ser reunidas sob dois títulos: razão e experiência.

\section{$\underline{\text { Razão }}$}

\section{a. Razão como Raciocínio Válido}

$\mathrm{O}$ instrumento tido como característico do conhecimento humano é o raciocínio. E julgamos poder atingir a verdade por meio do raciocínio correto. A lógica propõe-se a estudar os critérios de verdade formal, ou validade, de tal raciocínio critérios gerais para determinar se a conclusão de um argumento decorre de suas premissas, não importando quais sejam elas. Só o raciocínio dedutivo pode reivindicar esse tipo de justificação.

\section{b. Razão como Razoabilidade}

O sentido comum de "usar a razão" não remete apenas ao raciocínio dedutivo, mas ao conjunto de habilidades compreendidas como comportamento racional. Isso inclui formar e compreender conceitos, adquirir e empregar a linguagem, constituir crenças acerca do mundo e agir de acordo com elas.

\section{Experiência}

O conhecimento por experiência tem origem em algum tipo de percepção: por meio dos sentidos, enquanto percepção atual, ou recordada, pela via da memória; ou por introspecção, enquanto percepção de sensações internas, emoções e estados mentais. Mas a organização da experiência em conceitos e inferências é matéria de nossos raciocínios acerca da experiência. E embora não possamos contar com os critérios precisos da lógica para aferir tais raciocínios, avaliamos os argumentos acerca da experiência como sendo mais ou menos plausíveis, possíveis, prováveis ou razoáveis.
Lógica Informal, Retórica e Argumentação (COPI, 1982; SALMON, 1993)

\section{Argumentos acerca da Experiência}

\section{a. Causa e Efeito}

O conhecimento acerca da experiência tradicionalmente teve seu eixo na relação entre causa e efeito. As atribuições causais podem ir de causas particulares a gerais, passando por vários graus de generalização. A relação de causalidade pode ser tratada em termos de condições necessárias e/ou suficientes.

\section{b. Generalização}

O método de chegar a proposições gerais ou universais, partindo dos fatos particulares da experiência, é chamado de generalização indutiva. $\mathrm{O}$ argumento por generalização estende para um grupo, conjunto ou população uma alegação feita para uma parte dele, uma amostra. $\mathrm{O}$ conhecimento acerca da amostragem é chamado evidência indutiva para a generalização, termo que designa quer o argumento todo ou apenas sua conclusão. Tipicamente, a estatística desenvolve técnicas de amostragem e generalização.

\section{c. Analogia}

Comparações fazem parte de nossa linguagem comum, e são expressões favoritas dos poetas. Quando assim empregadas, apenas sugerem argumentos, mas não os explicitam. A mera comparação torna-se raciocínio por analogia quando é parte de um argumento. Se tirarmos uma conclusão acerca de um dos elementos da comparação, quanto ao outro deveríamos poder concluir o mesmo.

\section{d. Caso ou Exemplo}

Quando argumentamos, frequentemente recorremos a exemplos, quer na vida comum, quer nas exposições teóricas. O recurso a casos conhecidos por experiência é um método prático de delimitação do alcance de conceitos e argumentos. Quando exemplos acompanham a apresentação de uma definição, podem querer mostrar que algo se encaixa na definição, ou que nem tudo se encaixa na definição, ou ainda apontar a diferença entre a definição e outras noções que conhecemos. Ou podem mostrar que uma proposição universal 
é falsa: exemplos bem-escolhidos contrariam generalizações feitas apressadamente. Finalmente, podem mostrar que um argumento não é válido, ou é fraco, evocando fatos e casos possíveis em que as premissas seriam verdadeiras e a conclusão falsa.

\section{e. Falácias Não Formais}

As falácias lógicas são erros de raciocínio ou de argumentação, erros que podem ser reconhecidos e corrigidos. O objetivo de um argumento é expor razões que sirvam de suporte para alguma conclusão. Um argumento comete uma falácia quando as razões apresentadas, de fato, não sustentam a conclusão.

\section{ConhecimentoCientífico(MANDELBAUM, 1966;} HOSPERS, 1997)

\section{Leis e Probabilidade}

A ciência poderia ser descrita como a busca por regularidades e invariantes na natureza. As uniformidades que a ciência busca nos eventos são enunciadas em proposições universais denominadas leis da natureza. Mas o que parece ser uma lei universal muitas vezes exige correção, ou qualificação, decorrente das controvérsias e mudanças de paradigma na história das ciências. Confirmar uma afirmação é torná-la provável em algum grau. Isso porque nunca podemos verificar plenamente mesmo a mais simples generalização acerca da natureza. Em geral podemos dizer que temos evidência para considerar uma afirmação verdadeira, mas não que sabemos que é verdadeira.

Para construir uma teoria científica são necessárias muitas observações empíricas; e são necessárias outras tantas para derrubá-la. Os cientistas em geral se apegam às teorias já existentes e bem-estabelecidas, porque elas consistem em sistemas altamente coerentes de proposições. Se uma dessas alegações apresenta problemas, pode sempre ser modificada ou substituída sem alterar o arcabouço principal do sistema teórico. Contudo, nenhuma teoria científica está protegida para sempre da não confirmação. Apenas, exige-se muita evidência não confirmatória até que a teoria seja abandonada.

A ciência não fornece certeza lógica. Os fatos observáveis nunca provam a teoria: no máximo eles apenas a confirmam em algum grau. Nunca se pode deduzir uma teoria dos fatos observados; porém, a teoria pode fornecer uma explicascão dos fatos observados. O conhecimento científico visa a explicar por que muitas coisas ocorrem do modo que ocorrem. As explicações científicas em geral são formuladas dentro de uma teoria. Enquanto conjunto geral de enunciados, uma teoria nunca é provada, isto é, estabelecida de modo conclusivo, no mesmo sentido em que a conclusão de um argumento válido dedutivo é considerada provada. As teorias estão sempre sujeitas a revisões à luz de investigações futuras.

\section{Teoria e Observação}

A ciência procura revelar um mundo de entidades inobserváveis e forças invisíveis: ondas, partículas, todas inter-relacionadas e estruturadas num nível muito mais profundo do que aquele da experiência comum e da observação ordinária. Mas o estatuto de "realidade" e "veracidade" dessas entidades pode ser questionado. Isso mostra o quanto, na própria discussão epistemológica sobre a ciência, não há consenso sobre o discurso científico ser sempre a melhor tradução da realidade.

As discussões sobre a realidade dos objetos da ciência no fundo reforçam o realismo de senso comum. Afinal, a ciência não parece oferecer uma explicação indubitável sobre a natureza da matéria. O fato de a ciência nos dizer, por exemplo, que a mesa consiste de partículas em movimento vertiginoso e espaços vazios não torna ilusória a percepção que temos dela como objeto sólido. A pesquisa da matéria tem sempre como referência o mundo da experiência comum, dos objetos de "médio porte" que continuam a ser nosso ponto de partida e padrão de aferição e comparação. Afinal, é o modo de operar de nosso aparato perceptivo que serve de modelo para os aparelhos que potencializam e aperfeiçoam o que pode ser percebido. Assim como é o nosso modo de raciocinar que produz as teorias acerca da percepção.

Exercícios (HOSPERS, 1997; COPI, 1982; EPSTEIN, 1999; SALMON, 2013):

1. Os conhecimentos atribuídos aos animais são da mesma natureza que o conhecimento humano? 
a. O cão conhece seu dono?

b. O coelho sabe que vegetais fazem bem para ele?

c. $\mathrm{O}$ gato sabe que pode subir em árvores? $\mathrm{O}$ cão sabe que não pode?

d. Na escala de comportamento cognitivo que se inicia no grau zero do mero instinto, progredindo em complexidade através da aprendizagem, onde se inicia o conhecimento?

e. Só o homem conhece? Por quê?

2. Discuta os critérios para o uso da palavra "existe" em cada caso seguinte:

a. Animais existem.

b. Dores existem.

c. Magnetismo existe.

d. Fantasmas existem.

3. Comente a seguinte afirmação: "Você não estava lá. Eu sei que o que vi era uma nave espacial tripulada por extraterrestres!".

4. Explique tão precisamente quanto puder:

a. Como sabemos que uma certa experiência sensorial é alucinatória?

b. Como sabemos quando uma certa experiência sensorial é ilusória?

5. Quais das afirmações seguintes você aceitaria, ou rejeitaria, e por quê?

a. Há uma girafa nesta sala, invisível e intocável.

b. Há ondas de rádio nesta sala, invisíveis e intocáveis.

c. Há átomos em cada porção de matéria, invisíveis e intocáveis.

6. Que tipos de experiência uma pessoa deve ter para formar uma ideia de cada um desses conceitos?
a. Espaço.
b. Movimento.
c. Oportunidade econômica.
d. Probabilidade.
e. Bem-estar social.

7. Avalie as seguintes analogias, examinando se as semelhanças são mais relevantes que as diferenças: a. Cães devem ser tratados humanamente. Como alguém se sentiria preso numa jaula o tempo todo e sendo submetido a experimentos? Ou simplesmente acorrentado o dia todo? Ou sendo espancado cada vez que fizesse algo errado?

b. É mais fácil um camelo passar pelo buraco de uma agulha do que um rico entrar no Reino dos Céus.

c. O mundo é um palco e os homens e mulheres meros atores.

d. Se matar é errado, por que punir os assassinos com a morte?

e. A proibição de armas de fogo não vai diminuir os crimes. Afinal, tornar as drogas ilegais não diminui os problemas com elas.

8. Avalie as seguintes generalizações, examinando se a amostra é relevante para o aspecto generalizado:

a. Toda vez que um estranho se aproximou do portão, Rex latiu. Rex sempre latirá para estranhos.

b. Não vá ao Nordeste em dezembro. É quente demais.

c. Todos dizem que chá de erva-doce é bom para a gripe. Você deveria experimentar.

d. Todo aluno que conheço nesta universidade pratica esportes ou namora alguém que pratica. Acho que a maioria dos alunos aqui está envolvida com esportes.

9. Para cada uma das afirmações abaixo, apresente um exemplo que fortaleça ou enfraqueça a generalização proposta.

a. Todos os gatos matam passarinhos.

b. Nenhum restaurante tipo fast-food oferece comida saudável.

c. Quando a quantidade de moeda em circulação aumenta, há inflação.

d. Cada vez que aumenta o salário-mínimo, há desemprego.

e. Todos os usuários de heroína começaram com maconha.

f. A escassez de víveres causa revoluções.

10. Nos casos apresentados no quadro a seguir, A se relaciona com B enquanto condição necessária, suficiente, ambas ou nenhuma? 


\begin{tabular}{|l|l|l|}
\hline COLUNA $A$ & COLUNA $B$ & CONDIÇÃO \\
\hline Febre & Doença \\
\hline Decidir erguer a mão & Erguer a mão \\
\hline Correr & Sentir fadiga \\
\hline Desligar o "plug" & Rádio não funciona & \\
\hline "Plug" inserido na tomada & Rádio funciona \\
\hline Pedra atingir janela & Vidro quebrado \\
\hline Ocorrência de fricção & Ocorrência de calor & \\
\hline Chuva caiu na rua & Rua molhada \\
\hline
\end{tabular}

\section{Considerações Finais}

A proposta das oficinas convoca os recursos da lógica informal e da teoria da argumentação para apostar nos benefícios do exercício do pensamento crítico. Mas defende ser esse exercício melhor compreendido e aproveitado se associado a uma introdução à Epistemologia. Essa introdução segue os moldes das introduções à análise filosófica feitas para alunos de Filosofia e utilizadas quase que exclusivamente nos países de expressão inglesa. Elas não enfatizam definições ou regras, mas são construídas sobre problemas. A ideia é estimular a reflexão sobre os temas correlatos ao do conhecimento a partir das concepções de senso comum, conduzindo o estudante a refletir de modo aprofundado e preparando-o para a aquisição de conhecimentos complexos de forma ampla e crítica.

Entendemos que essa abordagem permite capturar a atenção do aluno ingressante de modo rápido e eficiente na reunião de ferramentas teóricas, conceituais e de linguagem para auxiliá-lo a acompanhar o curso escolhido de forma muito mais proveitosa e com maior engajamento. Esse preparo pode representar a diferença pretendida entre uma ciência reprodutiva e as concepções inovadoras tão buscadas para liderar a pesquisa no país.

\section{Referências Bibliográficas}

APPIAH, K. A. Thinking it Through: an Introduction to Contemporary Philosophy. New York: Oxford University Press, 2003.
AUDI, R. Epistemology: a Contemporary Introduction to the Theory of Knowledge. London: Routledge, 1998.

AYER, A.J. O Problema do Conhecimento. Lisboa: Ulisseia, s/d.

BLAGKBURN, S. Dicionário Oxford de Filosofia. Rio de Janeiro: Jorge Zahar Editor, 1997.

BLANCHÉ, R. \& DUBUCS, J. P. História da Lógica. Lisboa: Edições 70, 2001.

BURKE, P. Social History of Knowledge: from Gutenberg to Diderot. London: John Wiley \& Sons, 2013.

CHISHOLM, R. Teoria do Conhecimento. Rio de Janeiro: Zahar, 1974.

COPI, I. M. Introduction to Logic. New York: Macmillan, 1982.

CORNMAN, J. W.; LEHRER, K. \& PAPPAS, G. S. Philosophical Problems and Arguments: an Introduction. 4. ed. Indianapolis: Hackett, 1992.

DANCY, J. Epistemologia Contemporânea. Lisboa: Edições 70, 2002.

EPSTEIN, R. L. Critical Thinking. Belmont, CA: Wadsworth, 1999.

FISCHER, A. A Lógica dos Verdadeiros Argumentos. Lisboa: Ed. Novo Conceito, 2008.

FLEW, A. Pensar Direito. São Paulo: Cultrix, 1979.

HAACK, S. Philosophy of Logics. Cambridge: University Press, 1978; ed. brasileira: Filosofia das Lógicas. São Paulo: Editora Unesp, 2002.

HOSPERS, J. An Introduction to Philosophical Analysis. London: Routledge, 1997.

HUISMAN, D. \& VERGEZ, A. Compêndio Moderno de Filosofia. Rio de Janeiro: Freitas Bastos, 1968. vol. I: A Ação; vol. II: O Conhecimento.

LEHRER, K. Theory of Knowledge. Boulder: Westview Press, 1990. 
MANDELBAUM, M. Philosophy, Science and Sense Perception. Historical and Critical Studies. Baltimore: Johns Hopkins University Press, 1966.

MORTARI, G. Introdução à Lógica. São Paulo: Ed. Unesp, 2001.

MUSGRAVE, A. Common Sense, Science and Scepticism, A Historical Introduction to the Theory of Knowledge. Cambridge: Cambridge University Press, 1993.

PEIRCE, C. S. "The Fixation of Belief: How to Make our Ideas Clear; Some Consequences of Four Incapacities". In: Selected Writings (Values in a Universe of Chance). New York: Dover, 1966.

PLATÃO. Teeteto. Tradução de Carlos Alberto Nunes. Belém, PA: EDUFPA, 2001. Menon. São Paulo: Ediouro, 1960.

POPKIN, R. H. A História do Ceticismo de Erasmo a Spinoza. Rio de Janeiro: Francisco Alves, 2000.

RUSSELL, B. Os Problemas da Filosofia. Lisboa: Armando Amado, s/d.

SALMON, M. H. Introduction to Logic and Critical Thinking. 6th ed. Boston, Mass.: Wadsworth, 2013.
SALMON, W. C. Logic. 3rd ed. Englewood Cliffs, N. J.: Prentice-Hall, 1983; ed. brasileira: Lógica. 3. ed. Tradução de Álvaro Cabral. Rio de Janeiro: LTC, 1993.

SCHOPENHAUER, A. Como Vencer um Debate sem Precisar Ter Razão; em 38 Estratagemas (Dialética Erística). Rio de Janeiro: Topbooks, 1997. [Há outras traduções em português com títulos similares.]

SEXTO EMPIRICO. Outlines of Scepticism [Hipotiposes Pirronianas]. Trad: J. Annas e J. Barnes. Cambridge: Cambridge University Press, 1994.

SHAPIN, S. \& BARNES, B. (eds.). Natural Order: Historical Studies of Scientific Culture. Beverly Hills, Calif.: Sage Publications, 1979.

STRAWSON, P. Análise e Metafisica. São Paulo: Discurso, 1992.

VERDAN, A. O Ceticismo Filosófico. Florianópolis: Ed. da UFSC, 1998.

WESTON, A. A Rulebook for Arguments. Indianapolis; Cambridge: Hackett, 1987. Ed. em português: A Arte de Argumentar. Tradução de Desidério Murcho. Lisboa: Gradiva, 1996.

Publicado em 11/11/2016. 